\title{
Conversations about research supervision - enabling and accrediting a Community of Practice model for research degree supervisor development
}

\author{
Geof Hill and Sian Vaughan
}

School of Education and School of Art, Birmingham City University, Birmingham, United Kingdom

School of Education, City North Campus, Perry Barr, Birmingham B42 2SU, UK geof.hill@bcu.ac.uk

\begin{abstract}
The authors' lived experience of devising a professional development programme for research supervisors and securing SEDA (Staff and Educational Development Association) accreditation informs this paper. Our first purpose is to outline the programme and discuss its uniqueness in using a community of practice model (Wenger, 1998) in conjunction with practitioner inquiry (Stenhouse, 19981) for developmental and for assessment processes simultaneously. The second purpose is to discuss the challenges and benefits in securing SEDA accreditation for the programme, and how we managed to do this whilst retaining the richness of the conversations that colleagues find rewarding and useful. In sharing our model, we aim to encourage others to think about how dialogic and community of practice approaches might be embedded in professional development and accreditation opportunities in their own institutions.
\end{abstract}

Keywords: $\mathrm{PhD}$; supervision, community of practice

\section{Introduction}

This paper is written with a view to advancing conversations about and in the spirit of communities of practice (Wenger, 2010). The authors are both academics at a university in the United Kingdom (UK), engaged in and encouraging their colleagues to begin and sustain conversations about research supervision as an academic practice. We initiated a research supervisor professional development programme based on a community of practice (Wenger, 1998) model, and sought SEDA-PDF (SEDA Professional 
Development Framework) accreditation for the programme as professional development provision.

In this paper we have written from a position of practice-led inquiry (Gray, 1996) as researchers and practitioners. We further see that positioning as part of a broader agenda often referred to as 'the practice turn' (Schatzki, Knorr-Cetina and von Savigny, 2001) that argues for situated study of professional practice in specific professional settings. This paper reflects on the experience of enabling conversations about supervision as part of a strategic approach to embed reflexivity and a Community of Practice approach to research degree supervisor support and development in our university.

Research supervision discourse has for some time emphasised the value of reflective practice (Johnson, 1995), and maintains this agenda in recent contemporary higher degree research literature encouraging supervisors to audit their own practice, such as Lee's (2012) framework for research supervision and Taylor's $(2015,2016)$ supervisor questionnaire. Our approach takes reflexivity from a private practice to a communal one whilst maintaining the personal and individual focus through individual practitioner inquiries.

Our paper will cover briefly the provenance of research supervision practice and the authors' practitioner provenance that led us into initiating the community of practice. Our use of the term 'provenance' comes from usage in relation to works of art that indicates the history and ownership of an artefact. The migration of the term to practice-led inquiry maintains that every practice has a history, and that each practitioner engaging in that practice also has their personal history that illuminates the practice (Hill, 2014). We then outline our professional development programme 
modelled on Wenger's (1998) Community of Practice and reflect on our lived experience in seeking SEDA accreditation for the programme.

\section{Community of Practice provenance}

Whilst our intentions in this paper are to focus on the application and accreditation process for our particular use of a community of practice approach, it is nonetheless worthwhile to briefly reflect on the provenance of 'community of practice' itself. Originating from the work of Wenger and Lave (1991) as analytical critique to support a more social theory of learning, a community of practice entails three key elements domain, community and practice. In our context these are doctoral study, our research degree supervisors, and the academic practice of research supervision.

The popularity of the idea of community of practice has led to its wide-scale adoption, and also to growing criticism of it in the literature (Hughes 2007, Kimble 2006, Tight, 2015). Concerns have been raised about its commercialism by management consultancies and about 'diversity of usage and shift in usage, the lack of attention paid to power relations and the relative attention given to community as opposed to practice' (Tight ,2015, 118). However, as Tight (2015) concludes, as a theory, community of practice remains useful for thinking about academics, their students and how they work together. We adopted Wenger's $(2010,2)$ notion of a community of practice that recognises practitioners as meaning making entities in a social world and align with Wenger's $(1998,72-3)$ theory of social learning articulated as 'a community ... [with] mutual engagement ... a joint enterprise ... [and] a shared repertoire'. As Cater-Steele, McDonald, Albion and Redmond (2017) have suggested, in Higher Education this 
sharing of practice is seen to make explicit what were often considered tacit academic practices.

\section{Practice provenance}

The practice of research supervision has presumably been in existence as long as and parallel to research practices themselves, and was brought into academic practice with the shift of universities to become places of research (Noble, 1994). Despite this long provenance, however, discourse surrounding research supervision appears to have emerged relatively recently and grown quickly (Bastalich, 2017). There is now a growing worldwide discourse about research supervision that, whilst doctorate structures vary around the world, as a common academic practice still has threshold concepts of advancing research through mentoring emergent researchers (e.g. Lee 2012; Wisker 2012). Within the higher education literature it is recognised that research supervision practice is a practice filled with rich traditions but is one that is also still seen as a private or hidden practice (Manatunga, 2005) fostered by what Kelly (2017) terms the dyadic inheritance of doctoral pedagogy. Thus since the mid1980s, there has been an explicit agenda in the literature to examine research supervision practices with a view to helping professionals become much more aware of the professional choices they make in undertaking research supervision. Such agendas also enable research supervisors to address institutional and sector requirements for their own professional development (e.g. QAA 2013; RCUK 2016). Early examples of this approach are evident in Phillips and Pugh (1987), Salmon (1992) and Delamont, Atkinson \& Parry (1997) who sought to make transparent research supervision practices by publishing their own experience as guides and illuminators of the practice. In Education practice, this reflecting on one's own practice aligns with Stenhouse's (1981) notion of Practitioner Research. 


\section{Practitioner provenance}

Like many former polytechnics in the UK, our University emerged from an amalgamation of several colleges with a focus on professional and vocational education. Becoming a university in 1992, it began to develop a more explicit research agenda although doctoral education had existed in some subject areas since the early 1980s. It now has a fast-growing PGR community that has effectively more than doubled within the last five years, and therefore there are growing numbers of staff engaging in research degree supervision. In this context, a review of supervision training by the University's Research Committee in 2015 concluded that staff needed support and development opportunities around research supervision that went beyond discussion of the University's regulations and procedures for doctoral degrees, which until then had been the predominant feature of research supervision professional development. The Research Committee agreed on a professional development model for research supervisors that started with the policy framework supporting and guiding research practices and then extended that knowledge with discussions based on a community of practice. The aim was to bring together groups of academic professionals to talk about a common practice and through this dialogue, advance each individual's own understanding and practice.

The authors of this paper drove the initiative. One of the authors had undertaken his own doctoral degree focussed on Higher Degree by Research practices, including research supervision. A thirteen year post-doctoral appointment at Queensland University of Technology (Australia) helped develop specialisation in research supervision. He also initiated a blog to support research supervisors more widely (https://supervisorsfriend.wordpress.com/). The other author has twenty years' experience of teaching in Higher Education working within an Art School. She is 
Research Degrees Coordinator for the PhD programme in Art \& Design and leads a Supervisor Development Programme for her Faculty. Both thus have histories as academics supervising doctoral candidates, in supporting supervisor development and have active research interests and publish in the field of doctoral education.

\section{Our model and the pilot iteration of the community of practice}

In summary, our model for a Community of Practice around Research Supervision occurs as six 90-minute discussion sessions occurring one per month, with a two-month lead into the final session, to enable participants to investigate their own research supervision practices ahead of sharing those findings in the community. Embedding practitioner inquiry within, and scaffolded by the community of practice, is seen as what distinguishes this programme from otherwise similar professional development (CaterSteele et al, 2017). The programme runs across seven months and is purposefully limited to groups of approximately twelve academics.

The community of practice is designed around five catalyst questions for discussion. Each session (and thus catalyst question) is focused on a specific aspect of research supervision and is supported by the preparatory reading distributed to participants in advance. The questions are:

- Question 1: Who am I as a participant of this community of practice?

- Question 2: What prior knowledge do I bring to the practice of research supervision?

- Question 3: What is good research supervision?

- Question 4: What resources can I use to support my aim of improving my research supervision? 
- Question 5: How will I know when I have achieved my aim of improving my research supervision?

These questions have been devised in relation to the programme leaders' own research expertise and experience in the field of doctoral pedagogy and research supervision and in relation to the literature. They explicitly acknowledge that through participation in a community of practice 'we define with each other what defines competence in a given context' (Wenger 2000, 229). The rationale for this format is in line with the philosophy of the programme that participants will need scaffolding to devise a suitable practitioner inquiry appropriate to their own research supervision practice and identified development aims.

As well as distributing the catalyst material, each conversation is documented and then shared in the community. Learning in each session is thus reinforced through the distribution of notes afterwards for review and as a prompt for individual reflection. The notes provide a summary of the discussion as well as further details of literature and resources identified during the conversation. Participants are encouraged to review the notes and are given the opportunity to suggest clarifications and additions.

In the fifth conversation, participants are encouraged to identify their forthcoming individual practitioner inquiries alongside discussing resources that might support their on-going practice such as the wealth of available literature. Participants are given a list of sample inquiries, but as prompts rather than prescription, and we stress that they are free to propose an inquiry appropriate to their own experience and concerns. By the time of their final presentations, participants will be able to comment on how their application of new knowledge and skills has impacted on their practice as a supervisor. 
Participants are actively encouraged to view their practitioner inquiries as part of action plans for continuing professional development and thus in the sixth and final conversation the sharing of findings is explicitly positioned as interim reporting. They are prompted that presenting their findings within the community of practice provides a first vehicle for extending and potentially publishing their practitioner inquiry, and thus engaging further in the wider and growing professional discourse around research supervision.

A pilot group that included academic staff from each of the university's four faculties was established for the first community of practice in December 2015. Significantly the pilot included senior academic members of research management in the university, with all four Associate Deans for Research actively participating. The other participants included the staff with subject area responsibility for PGRs across the four faculties. This group of twelve people, plus the two facilitators (authors of this paper), also presented a variety of experience with some undertaking their first research supervisions since graduating themselves and others having a long record of supervision of doctoral students. The pilot community of practice concluded in June 2016. We have since completed another six iterations, and approximately 6 to 8 are planned for each academic year going forward.

\section{Lived experience of presenters in seeking SEDA-PDF accreditation for the programme.}

At the initial University Research Committee working group session it was recognised that SEDA PDF framework accreditation would be valuable in providing external validation for the professional development process, giving participants a portable qualification and benchmarking our practice nationally. So, alongside the instigation of a pilot group community of practice, we embarked on the SEDA accreditation process 
against the named award Supervising Postgraduate Research (SEDA n.d.). Significantly we started from a position whereby we knew what we wanted to do, how and why, rather than taking the SEDA outcomes as a starting point. Admittedly at times challenging, the SEDA mapping process was a useful device for auditing our programme. It challenged us to question the assumptions that underpin it and consider how the benefits of the programme could be more explicitly articulated and extended. The main areas of reflection generated by the SEDA mapping were around assessment, participation and facilitation, and each will now be discussed in turn.

\section{Assessment}

Assessment is an important SEDA agenda and for accreditation we needed to evidence participants' learning and development. In the final session of the pilot community, the strength of reported individual inquiries was more than sufficient to demonstrate to all present that it was possible to meet all the articulated objectives of the programme and remain within a community of practice philosophy. However, despite those present recognising the depth of the discussions as evidence of learning from the communities of practice, a more formal evaluation was required to make explicit participants' perceptions of their learning from the programme in a way that could be documented as evidence for individual achievement.

There is another programme in our University accredited against the same SEDA-PDF named award that supports supervisors of students on taught-Masters programmes which is assessed through a written portfolio. However, we sought a formal assessment that was in keeping with the collegial and collaborative nature of a community of practice and that emphasized the developmental conversations. This approach reflected wider agendas about the role of dialogue in professional development: 
In comparing dialogue with written assessment, dialogue offers benefits by allowing direct and immediate probing. The deeper message of dialogue is communicated through body language, voice and facial expression. This is hard to convey within the static medium of written text, making dialogue an important tool when exploring value-laden issues, perspective, attitudes and reflection. (Pilkington, 2013, p. 256)

Our experience of the conversations within the pilot group sessions clearly demonstrated that the discursive sharing of experiences amongst supervisors was foregrounding the exploration of values, approaches and different perspectives as participants reflected on supervisory practices across disciplines and with different students. It seemed counter-intuitive to then get participants to separate and each produce a written assignment. Our innovation, such that it is, was to use a community of practice model combined with practitioner inquiry for developmental and assessment processes simultaneously across a number of group dialogues to enable doctoral supervisors to gain a SEDA qualification.

The assessment requires participants to actively participate in the community of practice discussions, undertake practitioner inquiry into their own research supervision practices and provide peer feedback to fellow participants. This includes presenting their findings from their individual practitioner inquiries in the final session of the communities of practice in a five-minute oral report. Conciseness of these presentations is emphasised by focusing on rationale, analysis and reflection rather than description of context and methodology. The catalyst questions are structured to scaffold a practitioner's development of an inquiry appropriate and relevant to their own professional practice in research supervision. In addition, over the time of the programme and prompted by the distribution of notes, participants are encouraged to keep a reflective diary about their experiences of supervision and the community of practice. 
The key principles underlying our approach to assessment are gradual learning, individualized learning, the importance of 'social' feedback, and self-evaluation. The approach to attainment is holistic as we recognize that participants' experiences will vary and that there must be opportunities to meet the criteria by offering a range of evidence in context. We also understand that supervision periods can vary and this has to be taken into account in the process of evidencing good practice (for example, supervising a part-time EdD or part-time $\mathrm{PhD}$ can be a seven-year commitment under our regulations, so requiring a 'completion' as evidence for assessment would limit colleagues' opportunities to gain recognition for their professional development.) Our emphasis is on the process of the community of practice throughout all six sessions as developing a habit of mind of reflection and positioning research supervision as a practice subject to on-going development, rather than on a summative product for assessment that would act as a one-off approval or licence. This is why we explicitly position the presentations in the sixth session as interim reports, and the evidence considered for achieving the qualification encompasses participation across the different conversations, not just a final report.

\section{Participation}

A community of practice approach is based on the sharing of participants' experiences and reflections through conversation. In our model, an individual's participation is also encompassed in the consideration of evidence for achieving the SEDA-PDF award, thus we were prompted to reflect on how as programme leaders and facilitators we encourage participation. Several methods and strategies are used within the community of practice to encourage participation and practitioner sharing. Each discussion is inspired with a catalyst question and there is prior circulation of relevant preparatory resources (e.g. websites, journal articles). We also encourage participation through the 
explicit establishment and use of protocols to create and maintain an enabling atmosphere of respect and support (for example not talking over each-other and confidentiality) and proactively through direct invitations to comment to individual participants.

We recognise that participants will also vary as individuals in their introvertextrovert tendencies and that engagement can also be evident through other means. A participant may engage through the preparatory reading, individual personal reflection outside the sessions and active listening to the conversations, saying relatively little in the sessions but evidencing in what they do say, a deep understanding of the topics under discussion and go on to produce an effective practitioner inquiry. Where a lack of participation in the discussions is indicative of a lack of engagement in the programme, it is unlikely that a participant would be able to produce a practitioner inquiry of sufficient standard to both pass the programme and develop as a research degree supervisor. If such a situation were to arise (it has not as yet) the facilitators would discuss this openly with the participant involved outside of the sessions.

Once into the programme we found that continued engagement resulted from people being valued for their knowledge about the practice as well as their sense of growing understanding about research supervision. In our experience of the pilot programme, participation was actually a little overwhelming because of the vested interest by all the faculties. This resulted in quite a large community of practice in the pilot programme, with 14 participants around a table. It was also, perhaps, overlyweighted with relevant research expertise in Higher Education with six of the participants coming from the School of Education, thus there was more explicit discussion of meta-narratives, power and knowledge acquisition (e.g. Chomsky, 2006, Foucault, 1991; Freire 1996), than perhaps will be representative as the programme rolls 
out. The informal feedback obtained so far has been overwhelming positive colleagues praising the space and time for reflection, recognising the value of sometimes challenging discussions and wanting more, with repeatedly expressed desires to continue with the group meetings and the conversations around the experience of research supervision.

\section{Facilitation}

Preparing the documentation for SEDA accreditation placed a new lens on our own role as facilitators. It challenged us to consider how we could evidence participation for those not present, and how we could ensure quality, equivalence and the sustainability of the programme as the numbers of communities grow.

Each community of practice around research supervision at our institution has two facilitators and these facilitators undertake the assessment of participants in that cohort (although of course giving due regard to reflect the formative peer feedback provided by other community members during the sessions). Having two facilitators enables the subtle direction that might be needed to ensure that the learning objectives are met whilst enabling the flow of each conversation to develop for the particular cohort. It also enables the note-taking through which each conversation is documented and then shared in the community. These notes assumed a more prominent role when we recognised that they had to serve a dual process - as a reflective tool for participants in the community but also an audit trail for accreditation and moderation. Thus being a facilitator is a fine balancing act at times, and quite a nuanced skilled role. To try to ensure consistency and quality as we increase the scale of the programme and run several communities each year for a growing supervisory community, all facilitators are required to have previously successfully completed the programme. This is a key part of our underlying philosophy. Facilitators are themselves academics and research degree 
supervisors, thus they are part of not separate from the community that they are facilitating. The mapping process for SEDA accreditation also prompted us to create A Toolkit for Facilitators. As well as outlining the administrative requirements, the Toolkit discusses explicitly the strategies and techniques used to facilitate the conversations and it provides further details of both relevant resources and how links to the learning objectives can be made in each session should they not arise naturally in the course of the conversations. We have also established a further facilitators' community of practice that meets regularly. Led by ourselves as the programme initiators, this facilitators' community provides a forum for sharing experiences, supporting and encouraging reflection on facilitation, as well as for informal moderation of approaches to assessment.

Our programme does of course have more formal external moderation, crucial given that the facilitators are part of the communities whose individual participants they are assessing. It was decided that as far as possible, a staff member from our institution's Educational Development Service sits in on one of the sessions for each Community of Practice group and attends the facilitators' community of practice. In addition on an annual basis, an external moderator reviews a sample of the notes and is invited to attend one of the facilitators' community of practice sessions. The final presentation sessions are also audio-recorded, so that the moderator can if they wish compare the notes and recordings.

\section{Conclusions}

In sharing our model, we aimed to both add to discourses about supporting research supervisors and to encourage others to think about how dialogic and community of practice approaches might be embedded in professional development and accreditation opportunities in their own institutions. We have demonstrated that it is possible to use a 
community of practice model for developmental and assessment processes simultaneously that could be applicable to other areas of academic professional development.

It has been a rewarding experience to develop and run this model of Communities of Practice around Research Supervision. There have been obvious benefits of obtaining SEDA-PDF accreditation in terms of getting buy-in from both participants and senior management and in gaining recognition and visibility for research supervision as a previously somewhat overlooked academic practice. The process of applying for SEDA-PDF accreditation has in itself also had benefits. It has undoubtedly strengthened our programme in providing a mechanism for the explicit consideration of participation, assessment, quality assurance and sustainability. Evidencing participation has required more formal documentation and increased administrative burdens. We have recognised that participants' concerns and preconceptions regarding assessment can manifest as barriers in the early conversations. Happily, to date we have managed to reassure and encourage participants to trust the process and thus retained the richness of the conversations. Colleagues are finding the experience rewarding and beneficial.

Our focus on sharing experiences and reflections does not follow the common model of discussing detailed, often hypothetical, case studies (Brew and Peseta, 2004; McCormack and Pamphilon, 2002; Wisker, 2012, 65-72) as it foregrounds the participating supervisors' own lived experiences and it is less structured than the questionnaire approach for individual reflection proposed by Lee (2012) and Taylor $(2015,2016)$. Yet it arguably has the same breadth of coverage and in taking reflexivity from a private practice to a communal one we are still able to maintain the personal and individual focus through individual practitioner inquiries. As Kelly $(2017,68)$ states, 
often 'doctoral pedagogy is represented as a social practice'. Our community of practice model is itself a social practice. Our mix of novice and experienced supervisors from different disciplinary backgrounds encourages moving beyond the dominant discourses to consider alternative approaches. Our model foregrounds the solicitations of stories and articulations of practice, and through catalyst resources, helps research degree supervisors to situate their practice within the wider discourses on research supervision and doctoral pedagogy within the academy.

Our aim is through the community of practice model to engender a sense of community amongst research supervisors and to get them to recognise the value in meeting with other supervisors to discuss research supervision. These gatherings encourage them to attend the other, perhaps more traditional, training opportunities in order to continue and extend conversations about research supervision and doctoral pedagogy as an academic practice. Thus we can bring together groups of academic professionals to talk about a particular common practice and through this dialogue, advance each individual's own understanding and practice, evidence participants' development for individual awards, and engender enthusiasm for continued professional dialogues and participation in the broader range of development opportunities around academic practices. It is our belief that the community of practice model of professional development that we have developed, and its benefits, are transferable to other areas of academic practice.

\section{References:}

Bastalich, W. (2017). Content and context in knowledge production: a critical review of doctoral supervision literature. Studies in Higher Education, 42(7), 1145-1157, DOI: $10.1080 / 03075079.2015 .1079702$ 
Brew, A. and Peseta,T (2004). Changing postgraduate supervision practice. Innovations in Education and Teaching International, 41(1), 5-22. DOI:

$10.1080 / 1470329032000172685$

Chomsky, N. (2006). Language and mind. Cambridge: Cambridge University Press.

Delamont, S., Atkinson, P., and Parry, O. (Eds.) (1997). Supervising the PhD: A guide to success. Birmingham: Society for Research into Higher Education (SRHE) and Open University Press.

Foucault, M (1991). Discipline and Punish: The birth of a prison (new ed.). London: Penguin.

Freire, P. (1996). Pedagogy of the Oppressed ( $2^{\text {nd }}$ rev. ed.). London: Penguin.

Gray, C (1996). Inquiry through practice: developing appropriate research strategies. No Guru No Method? UIAH Helsinki.

Haigh, N. (2005). Everyday conversation as a context for professional learning and development. International Journal for Academic Development, 10(1), 3-16. DOI: $10.1080 / 13601440500099969$

Hill, G. (2014). Cycles of Action and Reflection in Action Inquiry (Methods). In D. Coghlan and M. Brydon-Miller (Eds) The Encyclopaedia of action research (pp. 234-239). U.K.: Sage.

Hughes, J. (2007). Lost in Translation: Communities of Practice. The Journey from Academic Model to Practitioner Tool. In J. Hughes, N. Jewson and L. Unwin (eds) Communities of Practice: Critical Perspectives, (pp.30-40). London: Routledge

Johnston, S. (1995). Professional development for post-graduate supervision. Australian Universities Review, (38) 2, 16-19.

Kelly, F. (2107). The Idea of the PhD: The doctorate in the twenty-first century imagination. London: Routledge.

Kimble, C. (2006). Communities of Practice: never knowingly undersold. In E. Tomadaki and P. Scott (eds) Innovative Approaches for Learning and Knoweledge Sharing, EC-TEL Workshop Proceedings, 218-234. ISSN 16130073

Lave, J. and Wenger, E. (1991). Situated Learning. Legitimate peripheral participation, Cambridge: University of Cambridge Press.

Lee, A. (2012). Successful research supervision: Advising students doing research. Routledge. Abingdon, UK. 
Manathunga, C. (2005). The development of research supervision: Turning the light on a private space. International Journal for Academic Development, 10(1), 17-30. DOI: $10.1080 / 13601440500099977$

McCormack, C. and Pamphilon, B. (2002). The balancing act: Exploring women's experiences of postgraduate study, supervision and workload: A workshop manual. Canberra: University of Canberra.

Noble, K. A. (1994). Changing doctoral degrees: An international perspective. Buckingham, U.K.: Open University Press \& The Society for Research into Higher Education.

Phillips, E. \& Pugh, D.S. (1987). How to get a PhD: A handbook for students and their Supervisors. Buckingham: Open University Press.

Pilkington, R. (2013). Professional dialogues: exploring an alternative means of assessing the professional learning of experienced HE academics, International Journal for Academic Development, 18(3), 251-263. DOI:

10.1080/1360144X.2012.717225

QAA (2013). UK Quality Code for Higher Education Chapter B11: Research Degrees. Gloucester: QAA.

Research Councils UK (RCUK) (2016). Statement of Expectations for Doctoral Training. Retrieved from http://www.rcuk.ac.uk/documents/skills/statementofexpectation-pdf/

Salmon, P. (1992). Achieving a PhD - ten students' experience. Staffordshire: Trentham Books.

Schatzki, T.R., Knorr-Cetina, K. and von Savigny, E. (2001). The Practice turn in contemporary theory. London: U.K.: Routledge.

SEDA (n.d.) SEDA-PDF Named Award Supervising Postgraduate Research. Retrieved from http://seda.ac.uk/supervising-postgraduate-research

Stenhouse, L. (1981). What counts as research? British Journal of Educational Studies. 29 (2), 13-114. DOI: 10.1080/00071005.1981.9973589

Taylor, S. (2015, April) Benchmarking supervisory development, paper at 2nd International Conference of Developments in Doctoral Education and Training, UK Council for Graduate Education, 30-31st March

Taylor, S. (2016) UK Professional Standards Framework (UKPSF) Dimensions of the Framework for Doctoral Supervisors. U.K.: Higher Education Academy 
Tight, M. (2015) Theory application in higher education research: the case of communities of practice. European Journal of Higher Education, 5 92), 111126. DOI: $10.1080 / 21568235.2014 .997266$

Wenger, E. (1998). Communities of Practice: Learning, Meaning and Identity. Cambridge: Cambridge University Press

Wenger, E. (2000). Communities of Practice and Social Learning Systems. Organisation. 7(2), 225-226. DOI: 10.1177/135050840072002

Wenger, E. (2010). Communities of practice and social learning systems: the career of a concept. In C. Blackmore, (ed). Social Learning Systems and Communities of Practice (pp.179-198). London: Springer-Verlag.

Wisker, G. (2012). The good supervisor. London: Palgrave Macmillan. 